\title{
Imaginario universitario: ¿Qué significa la universidad para los jóvenes estudiantes en Guadalajara?
}

\section{The University Imaginary: What does the University Mean to Student Youth in Guadalajara, Mexico?}

\author{
Liliana Natali Hidalgo Villegas \\ Universidad de Guadalajara \\ email: lilianahidalgo44@gmail.com \\ ORCID: orcid.org/0000-0001-7381-0635
}

Resumen:

Este trabajo aborda las significaciones imaginarias sociales de los jóvenes con respecto a la universidad. Mediante el análisis de 48 entrevistas se delimitaron aspectos puntuales en forma de esquemas interpretativos que los universitarios crean para dar sentido a su realidad. La revisión del concepto imaginario implicó una mirada hacia la exploración y reconstrucción de significados como parte de acervos de conocimiento instituidos socialmente; asimismo, dentro de los principales resultados: la universidad es construida a partir de su valoración positiva y negativa, su condición espacio-temporal y el papel que los universitarios tienen en la educación en México. Esta reflexión sirve como contexto para debatir acerca de la formación profesional y las realidades sustantivas de la vida universitaria.

Palabras clave: juventud, imaginario, significaciones, universidad.

\section{Abstract:}

This paper addresses youth's social imaginary significations regarding the university. By means of analyzing 48 interviews, certain specific points were delineated in interpretative charts the students created to make meaning of their reality. A review of the concept of the imaginary implied taking a look at exploring and reconstructing meaning as part of the heritage of socially instituted knowledge. Furthermore, the main results include the notion of the university as a construct based on its positive and negative evaluation, its spatial-temporary condition and the role that university students play in education, in Mexico. This reflection provides a context within which to debate professional training and the substantial realities of university life.

Keywords: youth, imaginary, significations, university. 


\section{Introducción}

o que se presenta a continuación es una mirada teórica-metodológica y la exposición de aspectos puntuales señalados por parte de 48 jóvenes entrevistados, estudiantes de la Universidad de Guadalajara, y lo que manifestaron en la construcción de significaciones que permitieron elucidar ${ }^{1}$ un imaginario universitario. La elección de los imaginarios y las significaciones imaginarias sociales como vía explicativa de la realidad se debe a la posibilidad de mirar un todo que se estructura sobre ciertas condiciones de cambio y movimiento que han de ser develadas; para ello se vuelve necesario contar con las herramientas que permitan determinar tanto el contexto en el cual se insertan los jóvenes en la educación mexicana como las posiciones desde las cuales la realidad es construida, percibida y asumida; es decir, dar cuenta de sus esquemas organizadores. Para tener una mejor comprensión entre aspectos contextuales y construcciones particulares es pertinente mostrar algunos indicadores sobre las condiciones actuales de la educación superior en México.

En términos generales, del sistema de educación superior mexicano, dividido en instituciones públicas y privadas, se desprenden universidades pedagógicas, interculturales, politécnicas, tecnológicas, entre otras; cada una de ellas se enfoca a cubrir necesidades educativas muy concretas. Según datos del Instituto Nacional de Estadística y Geografía (INEGI), para 2013 la matrícula escolarizada nacional de este nivel era de 3732396 estudiantes. Se ha observado un crecimiento al respecto ${ }^{2}$ tanto en modalidad escolarizada como abierta, lo que no solo expresa que la educación sigue siendo un modelo socialmente aceptable de reconocimiento, sino que también, al incrementarse el número de estudiantes se presentan una serie de problemas que impactan directamente en la forma de

1 La elucidación implica pensar lo que hacemos y hacer lo que pensamos en una condición histórico-social en la que convergen lo colectivo y lo individual en un tenso y constante proceso. Para ello es necesario interrogarnos reflexivamente sobre aquello que hacemos, lo que pensamos y también sobre lo que damos por sentado (Castoriadis 1983).

2 Para 2006-2007, en el sistema escolarizado se tenían alrededor de 2525000 estudiantes; en 2011-2012 la cifra se encontraba cerca de los 3274000, y en el ciclo 2012-2013 ya había 3500000. A nivel mundial, México tiene un crecimiento de dos puntos porcentuales por año, promedio similar al latinoamericano (dos puntos brutos por año). Dentro de sus publicaciones, la Asociación Nacional de Universidades e Instituciones de Educación Superior (ANUIES 2006) indica que la cobertura de educación superior se incrementó de $25.9 \%$ de la población entre 19 a 23 años en el ciclo 2006-2007, a 33\% en 2006-2007. 
concebir la educación y el significado del ingreso y la permanencia. En el caso específico que me ocupa, Jalisco cuenta con la tercera matrícula más alta del país, solo por debajo de la Ciudad y el Estado de México; en 2015 la Universidad de Guadalajara pasó a ocupar el segundo lugar a nivel nacional en matrícula con 116424 registros.

Al reflexionar sobre estos indicadores y contrastando con las condiciones actuales del mercado de trabajo en México aparece una tensión sobre el ideal que se tiene de la educación y las significaciones que amalgaman toda una serie de factores: desempleo, familia, el futuro deseable, intereses particulares, la educación en México, el futuro del país, etc. El INEGI registró que la población desocupada con nivel de estudios medio superior y superior tuvo un incremento al pasar de $38.09 \%$ en el segundo trimestre de 2013 a $46.34 \%$ en el mismo periodo de 2016.

Actualmente la educación sufre serias deficiencias con respecto a la integración al mercado laboral (Andere 2003, Flores 2005, Ibarra 2006, entre otros). Las políticas educativas ponen el acento en el incremento de la matrícula escolar y la eficiencia terminal como indicadores de desarrollo y prestigio hacia los centros educativos, siempre tratando de enmascarar los problemas de rezago escolar, deserción, bajo rendimiento, escasa calidad, saturación de carreras, cobertura sesgada, por mencionar algunos. Tomar en cuenta este escenario es importante para contextualizar la educación universitaria en el ámbito nacional y a su vez analizar cómo los jóvenes estudiantes se apropian de esta para la construcción de la realidad y por qué desean seguir una educación universitaria.

Ante la complejidad para dar cuenta de un imaginario como elemento estructurador de la realidad social, expondré en primer lugar un acercamiento hacia los imaginarios sociales desde el pensamiento de Cornelius Castoriadis, a fin de aclarar a qué refiere dicho concepto. A partir de su definición, y por supuesto de su distinción frente a otros conceptos, principalmente el de representación social, lo que se busca es establecer convergencias y divergencias, así como argumentar la elección de imaginario social. Posteriormente planteo algunos esquemas de interpretación metodológica para los imaginarios sociales de la universidad. Mi propósito es poner el acento en el concepto de imaginario social como herramienta teórico-explicativa que trasciende las interpretaciones de carácter funcionalista, psicológico o con base en racionalismos histórico-deterministas. Finalmente, incluyo algunos resultados y conclusiones obtenidos bajo 
este esquema de interpretación de la realidad por los jóvenes estudiantes con respecto a la universidad.

\section{Sobre el concepto de imaginario social}

Antes de explicitar en qué consiste el imaginario social, es pertinente señalar el contraste entre este concepto y el de representación social; Pérez y Enríquez (2016) realizan una distinción del imaginario desde la definición de Castoriadis donde este autor hace referencia a la creación originaria, el potencial que se tiene para la creación desde el magma de significaciones, mientras que las representaciones sociales parten de un proceso cognitivo-social para la construcción de significados sociales. Las significaciones imaginarias sociales son aquello que desde la teoría de los imaginarios permite al sujeto la inserción, reproducción y apropiación de una cultura determinada; constituyen el nexo para lograr que cada miembro de manera particular y colectiva sea agente partícipe de la sociedad, ya que vinculan al sujeto con la historia, los otros y su entorno. Lo que se conoce como mundo social no solamente pertenece a lo instituido, sin que por ello se niegue su carácter formador y condensador, ya que conforma ideas y ordenamientos instituidos por amplios procesos de participación social.

Para ayudar a la comprensión y caracterización de la teoría de los imaginarios conviene hurgar un poco en la historia. En 1898 Emile Durkheim enfatizaba, en Représentations individuelles et représentations collectives, la importancia de las «representaciones colectivas» en la dinámica social. Alude a estas como elementos construidos socialmente, portadores de significación e identificación social que son impuestos a los individuos. Al hacer también una distinción entre las representaciones colectivas y las representaciones individuales, ponía énfasis en que lo colectivo en ningún caso podría ser reducido a lo individual. Estas disertaciones únicamente consideran la dimensión instituida e identitaria pero dejan fuera el potencial de creación (génesis ontológica), que instituye a lo social.

Como parte de su tesis doctoral, La Psychoanalyse son imàge et son public (1961), Serge Moscovici retoma el trabajo de Durkheim para desarrollar el concepto de 'representación social' en el campo de la psicología social. Moscovici definió las representaciones como construcciones compartidas dentro de las interacciones sociales que permiten que los sujetos tengan referentes de sentido común para conectar con la realidad. El uso operativo de las representaciones 
sociales para analizar la realidad tiene una limitación al enfrentarse con lo histórico-social, donde la autopercepción de los sujetos es activa dentro de las significaciones sociales, es decir, en el imaginario. Al tiempo que Castoriadis adopta el concepto de 'imaginario' (1964), aparece la obra de Peter Berger y Thomas Luckmann, La construcción social de la realidad (1966). Estos últimos proponen la noción de 'universo simbólico' para nombrar una serie de significados socialmente instituidos, es decir, el universo simbólico es lo que permite dar cuenta de por qué el mundo es de determinada manera y no de otra; esta idea permite pensar el hacer, las prácticas y acciones como formas de comprender el imaginario social.

Para 1984 Denise Jodelet escribe Représentations sociales: phénomènes, concept et théorie donde retoma a Moscovici para el análisis de lo psicológico dentro de lo social; parte de la idea de que las representaciones conforman un tipo de conocimiento que responde al sentido común. Son las representaciones las que dotan a los sujetos de interpretaciones, lo que les permite actuar en consecuencia. Aquí las representaciones sociales son de carácter eminentemente práctico, en comparación con el imaginario; esto reduce las significaciones a meras representaciones individuales. Una de las coincidencias que se pueden encontrar en las formas antes expuestas de concebir las representaciones sociales es que aluden a modos concretos de relacionarse con los otros y el entorno, permitiendo así marcos comunes de interacción e interrelaciones. Las representaciones condensan infinidad de significados en sistemas interpretativos que dan sentido a la realidad, a la vez que construyen modelos de pensamiento socialmente válidos para guiar el actuar de los sujetos en la vida cotidiana.

El concepto de 'imaginario social', ${ }^{3}$ acuñado por el filósofo griego Cornelius Castoriadis, se ha utilizado de manera indistinta ${ }^{4}$ y en diversas áreas de conocimiento: psicoanálisis, antropología, psicología social, historia, sociología y filosofía. En el área de las ciencias sociales, los estudios que retoman ese concepto de imaginario han ido cobrando fuerza por el creciente interés en propuestas de

${ }^{3}$ El imaginario social desde este enfoque se desmarca de una visión objetiva de la realidad o de concepciones ligadas a modelos de corte explicativo-causal.

4 Para algunos autores lo imaginario alude a imágenes o a representaciones, mientras que otros destacan su carácter de significación y de construcciones de sentido. "Lo imaginario es para algunos un esquema de interpretación del mundo (Maffesoli) que orienta los comportamientos y facilita el ejercicio del poder (Baczko). Para otros alude a la producción de representaciones colectivas que favorecen la comunicación y la interacción entre los sujetos (Carretero). Castoriadis y sus seguidores (Lizcano Fernández) señalan que lo imaginario social se refiere a la construcción de significaciones que instituyen y mantienen unida a una sociedad» (Anzaldúa 2006). 
carácter interpretativo. Entre las diversas contribuciones que se han realizado en relación con el estudio de la institución imaginaria de la sociedad se encuentra Nerio Tello (2003), quien explica que la relación de la imaginación radical con el imaginario social no es de subordinación ni de utilidad, sino de confrontación y retroalimentación. Nicolás Poirier (2004) menciona que mediante la imaginación radical es viable la generación de la realidad como una representación o una imagen, lo cual es posible debido a la vinculación entre la psique y lo social. En el trabajo de Baeza (2000) se rescata que los imaginarios sociales constituyen matrices de sentido que sirven para la elaboración de sentidos que se verán plasmados en el discurso, el pensamiento y en la acción social.

Yago Franco (2003) sostiene que en la imaginación radical se encuentran contenidos la psique y lo social unidos, desarrollándose en varias etapas. En un primer momento se habla de la vinculación a través de la distinción de lo individual y lo social como categorías independientes dentro del imaginario radical; posteriormente, la unión mediante la represión de la psique a partir de lo social; y finalmente, una conexión desde las instituciones, las cuales introyectan en la psique del sujeto las significaciones sociales para conformar cierta clase de individuo. En relación con objetos empíricos concretos, Raúl Anzaldúa (2010) aborda diversas problemáticas sociales como: educación, docencia, comunicación, psicoanálisis y política; todas ellas teniendo como punto de referencia lo imaginario, concebido como creación de significaciones y sentido.

Castoriadis aclara en qué términos debe ser entendido lo imaginario: «lo imaginario no es a partir de la imagen en el espejo o en la mirada del otro. Más bien, el 'espejo' mismo y su posibilidad, y el otro como espejo, son obras de lo imaginario, que es creación ex nihilo» (Castoriadis 1983:10). El imaginario social y sus representaciones son una producción colectiva a partir de la cual las sociedades trazan sus identidades y objetivos, organizan su pasado, presente y futuro. Es aquello que plasma a los sujetos su visión del mundo, lo que modela sus conductas, estilos de vida y dirige su rumbo. En esa dimensión se identifican las diferentes percepciones de los hombres respecto de sí mismos y de los otros, ya que las representaciones, así como los imaginarios sociales:

Son referencias específicas en el vasto sistema simbólico que produce toda colectividad y a través del cual ella 'se percibe, se divide y elabora sus finalidades'. De este modo, a través de [estas representaciones e] imaginarios sociales, una colectividad designa su identidad elaborando una representación de sí misma; marca la distribución de los papeles y las posiciones sociales; expresa e impone ciertas creencias comunes, 
fijando especialmente modelos formadores como el del 'jefe', el del 'buen súbdito', el del 'valiente guerrero', el del 'ciudadano', el del 'militante', etcétera (Baczko 1991:28).

Los imaginarios existen en la medida de su capacidad para fundir símbolos y significados sociales en determinados acuerdos. Hay que dejar claro que lo imaginario no es reductible a lo simbólico y, viceversa, lo simbólico no puede reducirse a lo imaginario; sin que por ello se niegue la estrecha relación que guardan y el hecho de que no puede existir el uno sin el otro. En este sentido puede señalarse en un primer momento que lo simbólico y la significación son el medio donde reside lo imaginario, sin que estas sean sus únicas manifestaciones.

Juan Luis Pintos reflexiona sobre los imaginarios como «representaciones colectivas que rigen los sistemas de identificación y de integración social, y que hacen visible la invisibilidad social» (Pintos 1995:8). Este autor también apunta hacia el papel que juegan los imaginarios al proporcionar las categorías de comprensión de los social. Existe una integración en una matriz de experiencias subjetivas que se cristalizan como ideas, imágenes, símbolos, sentimientos, sueños y proyectos pertenecientes a determinada cultura. Estos mecanismos de comprensión de la realidad se vuelven particulares en la medida que se construyen sobre significaciones específicas ya instituidas y las experiencias propias de los individuos. Al igual que los mitos, los imaginarios se constituyen sobre referentes de percepción de la realidad.

Las significaciones de una sociedad son instituidas en la medida en que son aceptadas, asumidas y legalizadas, dando orden e identidad al conjunto social y a los individuos que lo conforman. Sin embargo, el imaginario no solamente se remite a dar cuenta de estructuras ya prefijadas de lo social. El significar/representar posibilita la existencia real del mundo, de las instituciones, del 'decir' y del 'quehacer' humano. Para caracterizar ese decir/hacer social, Castoriadis (1989) se remite a los conceptos de legein y teukhein. Por legein se entiende el 'decir', es aquello que permite organizar, realizar operaciones de distinción, elección, conteo, designación, etc.; es la creación humana. Por su parte el teukhein es el 'hacer'; reúne-adapta-fabrica-construye, se encarga de la finalidad e instrumentalidad, en referencia a lo que es, a lo que no es y podría ser; es acción social. A fin de que haya un efectivo funcionamiento de las instituciones es necesario que exista una implicación recíproca entre el legein y teukhein. Estos dos conceptos forman parte de la dimensión del imaginario, sirviendo de conducto a la lógica 
conjuntista-identitaria, con el propósito de ser reconocida e instituida dentro de lo social.

La propuesta de investigación que dirigió este estudio aboga por un análisis de los imaginarios sociales desde una perspectiva del ejercicio interpretativo de la realidad escolar. Bajo la lupa de los imaginarios, la universidad se muestra desde discursos sociales instituidos e instituyentes; prácticas; dinámicas y cambios en las significaciones, dando así claves para el análisis de los imaginarios en su dimensión ontológica constructivista, donde la realidad no es dato objetivo ni a priori, al contrario, es una construcción social particular que puede cambiar y reconstruirse con base en las significaciones propias de los sujetos. A partir de estas consideraciones, en el siguiente apartado se señala la metodología seguida para dilucidar la manera en la que se lleva a cabo este proceso de creación, incorporación y apropiación de significados universitarios.

\section{El método para imaginar la universidad}

Como se mencionó en la introducción, los datos presentados corresponden a entrevistas realizadas en la Universidad de Guadalajara ${ }^{5}$ a jóvenes en edades que rondan entre 19 y 28 años; el periodo de entrevistas fue de agosto de 2015 a enero de 2016. Al término del trabajo se contó con la participación de 16 jóvenes provenientes de cada uno de los tres centros temáticos seleccionados: Ciencias Económico-Administrativas (CUCEA), Ciencias Exactas e Ingenierías (CUCEI) y Ciencias Sociales y Humanidades (CUCSH), dando un total de 48 entrevistas. El discurso de los jóvenes se destaca a la universidad como semillero de imaginarios por el hecho de que los alumnos de una u otra forma, dejando por un momento de lado el tipo de motivaciones, deciden incorporarse a una educación universitaria; lo que significa que para hacerse partícipes de esta construcción social habría primero que encarnarla a manera de significación en lo particular y en su relación con el universo de significaciones con el que ya se cuenta. Por ello, cuando se habla de universidad se vierten en ella una serie de significaciones y simbolismos que constituyen una pauta en la manera de establecer las interac-

\footnotetext{
${ }^{5}$ La Universidad de Guadalajara en la zona metropolitana cuenta con seis Centros Universitarios Temáticos: CUAAD-Arte, Arquitectura y Diseño, CUCBA-Ciencias Biológicas y Agropecuarias, CUCEACiencias Económico-Administrativas, CUCEI-Ciencias Exactas e Ingenierías, CUCS-Ciencias de la Salud y CUCSH-Ciencias Sociales y Humanidades, los cuales albergan aproximadamente a 74763 alumnos.
} 
ciones sociales; quienes tienen la posibilidad de adentrarse en la educación superior ven cómo su concepción marca la forma en la que se configura el ritmo de la vida natural, social e individual de cada sujeto. Y si esto es así, es por el hecho de que la universidad no es algo que tenga una simple y única definición, es una construcción que se estructura en relación con un individuo, con un contexto y con una sociedad o cultura determinados.

Bajo este supuesto, pensar la universidad implica el análisis de la identidad, de la creación de un '«sí mismo»', tanto en el terreno individual como en el social, es decir, pensar en un universitario. Los fenómenos sociales no guardan un sentido per se, sino que existen en la medida en que les otorgamos una significación. Para Castoriadis (1983) todo aquello que se considera real proviene de un imaginario social que, mediante la institucionalización de un conjunto (magma) de significaciones particulares, le da sentido a cada cosa que nos rodea. La sociedad es entendida como un producto de la autoinstitución, un construccionismo social en el cual se materializa la realidad, la vida cotidiana, el surgimiento de la cultura, el orden y la participación social, considerando la realidad como producto de una construcción social, donde para cada uno de los sujetos la realidad cobra una significación particular. Lo que surgió en las entrevistas fueron textos donde se recuperaron las narrativas y los discursos de jóvenes universitarios, los cuales caracterizaban de manera sistemática propiedades, características y posicionamientos particulares del imaginario universitario; pensar la universidad como una articulación simbólica de imaginarios, como una institución que se forma en la medida en que quienes participan dentro y fuera de ella son capaces de otorgarle determinadas funciones, como un espacio en el cual quedan vertidas las expectativas de jóvenes hacia un proyecto tanto individual como colectivo, un proceso donde se ve cristalizado el imaginario colectivo. Aunados a esta perspectiva se suman los planteamientos de Pintos (2000) para desarrollar un análisis de las realidades sociales a partir de una visión constructivista sistémica.

Lo decisivo de esta teoría para nuestra reflexión sobre imaginarios sociales es que sustituye el principio de la identidad por el de la diferencia. Esto nos sitúa en una perspectiva constructivista que invalida la distinción materialismo/idealismo, que asume la operatividad de la teoría social como mecanismo de comunicación en los sistemas sociales, que integra el tiempo como la variable fundamental de las descripciones de las sociedades y que realiza una sustitución epistemológica compleja del principio de identidad y unicidad por el de la diferencia, la pluralidad, la recursividad y la reintroducción de la unidad de la diferencia en un lado de la distinción (Pintos 2000:5). 
En este sentido, es posible diferenciar los sistemas sociales y analizarlos desde su autodescripción; es así como se comprende a los imaginarios sociales, a partir de la construcción que realizan los involucrados sobre su propio sistema. Esta propuesta se separa un poco de la idea de Castoriadis (1983) sobre el magma, donde todo aquello que se considera como real proviene de un imaginario social que, mediante la institucionalización de un conjunto de significaciones particulares, le da sentido a cada cosa que nos rodea. Lo que se busca con este enfoque es mirar a los universitarios como producto de la auto-institución, un construccionismo en el cual se materializa la realidad, su vida cotidiana, la legitimación, el orden y su participación. De ahí que cobre tanta relevancia para este estudio lo instituido y los imaginarios sociales.

El imaginario social universitario es un conjunto de esquemas organizadores que son condición de representatividad de la universidad, tanto en un nivel general como en el marco de las experiencias particulares de cada estudiante. Lo imaginario se organiza como una compleja red de relaciones sobre la que se sostienen los discursos y las prácticas propias de la universidad. Las relaciones que se tejen como parte de las significaciones sociales, según las describe Cabrera (2006), entrañan posicionamientos de legitimación, integración, consenso (elementos entendidos como explicación, fuente de sentido y plausibilidad subjetiva, estimulan, permiten y prohíben la acción social de los jóvenes), cuestionamiento, crítica (reforma y cambio a partir de los significados que los jóvenes le otorgan su acción dentro de condiciones ya legitimadas), imaginarios radicales (sentido indiscutible e indiscutido, soporte de las articulaciones y las distinciones entre lo que importa y lo que no en la elección de la universidad y dentro de ella), así como modelos instituidos (marca una dirección de sentido que los jóvenes viven como normas, valores, lenguaje, imágenes y formas; así, las instituciones no son solo herramientas de creación sino formadores de subjetividades) e instituyentes (una significación propia desde la experiencia individual de los jóvenes).

Los imaginarios se encarnan en constructos legitimados, para este caso en particular, lo definido por la universidad (imaginario instituido universitario) y lo definido por la comunidad (imaginario instituyente y radical). Esta imaginación radical surge a través de la estrecha relación entre lo social y la psique del sujeto concebida como medio de creación, innovación, capacidad de construir y crear una realidad, de ver más allá de lo aparente y de tener la facultad de pensar diferente (Castoriadis 1994). La universidad como imaginario social se consolida desde la institución; lo instituido da legitimidad y reconocimiento dentro de la 
sociedad. Sin embargo, la universidad no solo es una entidad ya constituida, a partir de la apropiación y las múltiples maneras en que se crean relaciones con la universidad; se puede resignificar porque el imaginario social no es la suma de los imaginarios radicales.

Al concepto de imaginario no se le puede otorgar una forma única pues este es fuente de todas las formas y figuraciones que se pueden crear, y tratar de definirlo sería limitar su potencial para el análisis y la interpretación. Y si esto es así, ¿qué podría reunir el imaginario universitario en términos de expresiones empíricas susceptibles de análisis? Anzaldúa y Ramírez (2016) sostienen que una investigación en estos términos es posible mediante la exploración de «sus expresiones, de sus formaciones, que obligan a la reflexión, a la crítica, a la elucidación, donde el lenguaje juega un papel central [...] por el trabajo poético que forma, transforma y conforma aquello de lo que se habla, dilucidando las condiciones que hicieron posible las cosas por las que nos interesamos» (Anzaldúa y Ramírez 2016:29). Esto me lleva a acercarme a una construcción desde las experiencias, sentimientos y expectativas comunes en y de la universidad (referencias a estudios universitarios desde que estos comenzaron a ser parte de su proyecto de vida); y la vinculación de símbolos y significados sociales, dentro de acuerdos comunes (por ejemplo, las significaciones de formación-valor-estatus-éxito).

Para plasmar el imaginario de los jóvenes universitarios tomé, como eje rector en la construcción sistémica de las realidades, el código 'relevancia/opacidad'. Este código consiste en el análisis de la realidad como un todo integrado mediante el establecimiento de aquellas relevancias y opacidades presentes en la realidad de los sujetos. Cabe aclarar que al hablar de relevancia y opacidad no se hace desde una concepción de opuestos, al contrario, no se puede concebir el imaginario sino a partir de una condición de complementariedad. Pintos (2004) distingue esta relación desde una condición de 'presencia y ausencia' y lo compara con las técnicas fotográficas de imágenes en un plano: el polo positivo como lo relevante y el polo negativo como aquello opaco u obviado, pero sin el cual no hay realidad posible. Este código trata de construir la realidad más allá de un absoluto o linealidad, es decir, desde la complejidad. Tomando en consideración los señalamientos anteriores, en la figura 1 se exponen las dimensiones que considero más importantes, aunque no exclusivas, para la reconstrucción de un imaginario en torno a la universidad. 
Figura 1. Las dimensiones del imaginario universitario.

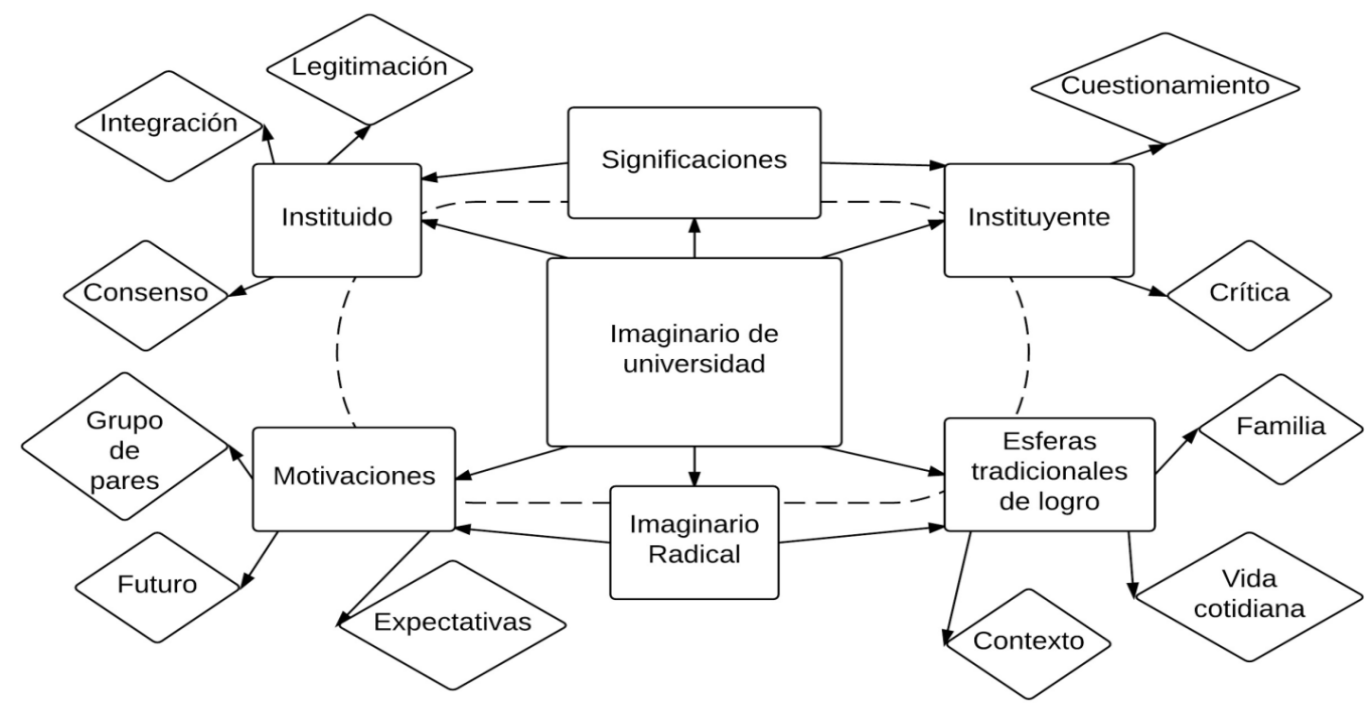

Fuente: Elaboración propia con base en la teoría de los imaginarios sociales.

Los universitarios son quienes describen la institución desde lo que para ellos es característico y señalando sus cualidades y defectos; al hacerlo elaboran un juicio desde su forma particular de significarla. En este sentido es necesario tener presentes dos formas básicas: 1) Identificar las formas en que los universitarios viven, sienten y proyectan la universidad, así como los motivos que los llevan a actuar de una forma determinada frente a esa realidad y 2) Establecer categorías respecto de la construcción social de imaginarios que hacen los estudiantes sobre la universidad. Esta información pudo dar cuenta de la posición que asumen los jóvenes ante la realidad. Es importante advertir que no todos los casos son definitorios respecto de posturas instituidas o instituyentes, más bien aparecen una serie de matices que habrá que contextualizar y clasificar para poder dar una explicación más fidedigna. La comunidad universitaria, en su doble papel dentro de lo instituido y lo instituyente, es la que se encarga de los procesos de creación y re-significación de lo simbólico. Como se describe a continuación, la participación activa de ellos es la que define las posibilidades de apropiarse de esta institución social y no simplemente considerarla como un paso más en la formación educativa; y a la inversa, también se encarga de reproducir, legitimar y dar permanencia a los patrones ya establecidos. 


\section{Cómo significan los jóvenes la universidad}

Dentro de la construcción de significados por parte de los jóvenes, la universidad adquiere un sentido de apropiación muy particular: el estatus del lugar donde es socialmente aceptable la adquisición de conocimientos con el mayor número de referencias entre los entrevistados; esto en comparación con la condición de una posible vinculación al servicio de la sociedad, la cual queda relegada entre las menciones por parte de los jóvenes. En este sentido ya se ha hecho referencia anteriormente a la manera en que Castoriadis (1989) muestra cómo la asignación de funciones es una condición que se presenta dentro de la institución, que es parte de un mundo de significaciones imaginarias sociales donde prevalece la doble definición entre las funciones y las significaciones.

En un primer momento, al cuestionar directamente sobre el por qué eligieron la Universidad de Guadalajara, surgieron agrupaciones semánticas que asignan significaciones en función de las características de la propia universidad como institución pública. Como elemento central, los jóvenes manifiestan la cuestión del prestigio que se obtiene al pertenecer a dicha institución, el prestigio como un elemento simbólico sustantivo.

Además de que es la más reconocida en la ciudad, es un orgullo pertenecer o ser parte pues, ser miembro de la universidad, y la elegí simplemente por eso. En realidad el hecho de ser Universidad de Guadalajara es como que más representativo, es lo que más me inspira (Daniel, 19 años, CUCEA, Administración).

Dentro de los presentes testimonios la construcción semántica advierte una estrecha relación entre el estatus que otorga pertenecer a la universidad, la función dentro del imaginario y como parte de un grupo más amplio, es decir, una adscripción a un grupo de universidades reconocidas dentro y fuera del propio contexto mexicano. A su vez, estas referencias hacia la calidad de la institución provienen de los círculos cercanos a los jóvenes, como es el caso de la familia o de entes abstractos, caracterizados por los pronombres indefinidos como: «las personas, la gente, algunos» que entran en la categoría de condiciones instituidas, socialmente legitimadas e instauradas a través de la historia de la propia universidad, como un acto de reproducción.

Como segundo elemento articulador dentro de la Universidad de Guadalajara se encuentra su cualidad de ser una universidad pública. Este campo adquiere 
mucha fuerza en el discurso de los jóvenes, ya que incide directamente en su contexto particular y familiar, donde la situación económica no les permite acceder a una universidad privada. La construcción simbólica de estos dos elementos (el prestigio y la naturaleza pública de la universidad) indica cómo la formación universitaria rescata características intrínsecas de esta institución en comparación con sus homólogas. Sin embargo, no se puede atribuir la totalidad de la elección a las condiciones de reconocimiento de la propia universidad o a las condiciones económicas de los jóvenes y sus familias; la propia formación también cuenta con una incidencia considerable dentro de lo simbólico, donde el significado de la educación como forma instituida por la sociedad cobra un sentido muy particular dentro del sujeto, ya que este le otorga una consideración desde las inquietudes y necesidades que él tiene como sujeto.

La ubicación espacial de la universidad como elemento de posibilidad destaca desde dos posturas distintas: por un lado tenemos quien señaló como factor la cercanía de la universidad con respecto a su actual vivienda y a su vez hubo quien la eligió por encontrarse en una ciudad como Guadalajara, aun cuando eso implicará vivir alejado de la familia y cambiar de residencia. Aquí ambos testimonios:

Porque era mi opción más factible económicamente y porque la carrera que yo quería era lo más cercano que tenían, que podía costear y que estuviera aquí en Guadalajara (Ignacio, 26 años, CUCEl, Mecánica Eléctrica).

Pues por la ciudad de Guadalajara, porque no quería quedarme en Zamora; sí hay universidades pero son muy malas. O sea, estaba aburrida de la ciudad en la que vivía, así que estaba pensando en Morelia, en otro lado, vivir en una ciudad más grande. Al principio fue difícil porque como no tengo familia aquí no conocía la ciudad, ni la gente ni nada y al principio sí fue muy difícil, o sea, para mí fue muy difícil porque no tenía ni amigos ni nada; pero mis papás siempre me apoyaron, siempre me dijeron está bien, "es un sacrificio que haces pero pues va a dar frutos porque vas a una buena escuela» y allí en Zamora no son tan buenas y reconocidas como la UdG. También porque desde la prepa había escuchado de la UdG. Muchos de Zamora se vienen a estudiar aquí, o sea, no me alcanza para pagar una particular, o sea, una de las grandes y esta pues está bien (Isabel, 20 años, CUCEA, Negocios Internacionales).

La condición de estatus que se presenta en lo simbólico desde lo que la universidad le otorga a los jóvenes guarda también relación con condiciones 
personales, las cuales se vuelven entrañables y modifican incluso la vida cotidiana de los universitarios:

Personalmente creo que mi criterio se amplió bastante. Yo cuando estaba en la preparatoria vivía como en mi burbujita; yo y mis amigos, y mis familiares y pum, hasta aquí llega, sí me daba cuenta de algunos problemas sociales, económicos, políticos de México pero no los conocía tan a profundidad como cuando ya empecé a estudiar a nivel licenciatura en la universidad. Me vuelvo un sujeto más pensante, más activo también porque antes en mi apatía para participar en cuestiones de movimientos sociales o de marchas, ya acá me doy cuenta que sí es importante tú, como sujeto, participar y apoyar los movimientos que tratan de atender ciertas problemáticas sociales. Ahorita soy una persona que quiero participar en todo, quiero apoyar en todo, si hay un movimiento, un grupo que están apoyando niños de la calle, órale; yo estudio comunicación, puedo gestionarte redes, trato de estar como participando aquí y allá y antes pues no, es su bronca, no la mía (Alan, 24 años, CUCSH, Comunicación Pública).

La construcción del estatus universitario no se realizó al azar, ni simplemente como resultado de las condiciones instituidas, sino que proviene de significaciones imaginarias sociales; aquí existe una implicación de lo individual y la parte histórico-social. Los trayectos que han elaborado los jóvenes desde la propia concepción de la universidad, pasando por la decisión de continuar sus estudios y finalmente lo que ellos esperan de la institución, se han caracterizado por entrelazar sus discursos en experiencias que involucran a la familia, la cultura, su contexto y a la sociedad. Más allá de la visión instituida de la universidad, legitiman el imaginario sobre prácticas sociales directas.

Rescatan tanto los elementos positivos como negativos de la universidad. Las reflexiones sobre este tema son diversas y enfocadas hacia la calidad que brinda la universidad en sus diferentes rubros. A fin de establecer un comparativo, la gráfica 1 destaca cómo de los 48 entrevistados, 98\% (47 jóvenes) reconoció aspectos positivos de la universidad; mientras que 73\% (35 sujetos) consideró que la universidad tenía algún aspecto negativo.

En el marco de estas relaciones, lo que se valora con mayor énfasis es el ambiente universitario, lo que para ellos representa la vida universitaria.

Los amigos, los compañeros; se pasa un rato ameno, y aparte, lo que me gusta mucho es de que en cada materia es un salón nuevo, un compañero nuevo y conoces muchísimas personas, de muchas carreras, de muchas edades, de diferentes lugares, 
Gráfica 1. Bueno y malo de la Universidad de Guadalajara.

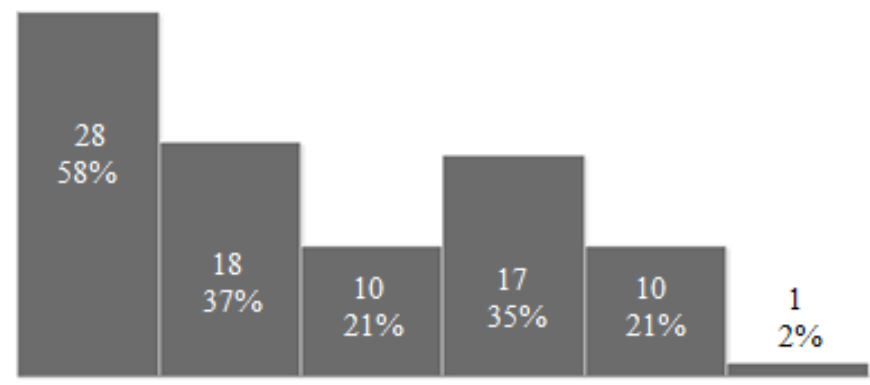

\section{bueno de la universidad}

ambiente carrera instalsciones profesores calidad colectivo

\section{malo de la universidad}

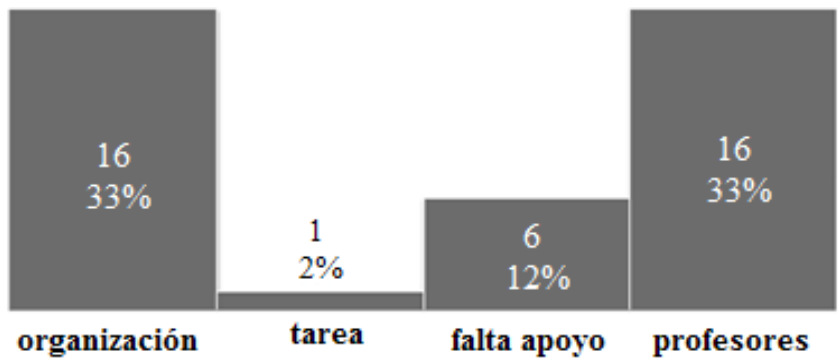

Fuente: Elaboración propia con base en el análisis de las entrevistas.

que tienen diferentes costumbres. Aprendo mucho de todas las personas y más como soy muy sociable, no puedo estar al lado de alguien si no le platico algo o le pregunto algo. Eso me ha ayudado mucho para crecer como persona, como estudiante y ya puedo conocer a más personas que vienen aquí (Fernanda, 23 años, CUCSH, Antropología).

Pues el ambiente universitario es la suma de varias cosas: los docentes, la docencia, las personas que me enseñaron que, además de ser personas, que para mí son extremadamente profesionales y éticos, y que finalmente se terminan por convertir en amigos tuyos; tus propios compañeros, las personas que están en el mismo proceso que tú que empiezas a conocer un poquito más, te abres un poco más con ellos, ves cosas en común, simpatizas con ellos. Sí te da cierto sentido de pertenencia a toda esa red, a toda esa gran cantidad de gente que es Universidad de Guadalajara, y yo creo que esa colectividad, esa cosa tan grande es lo que más me gusta de la universidad (Alan, 24 años, CUCSH, Comunicación Pública).

Los jóvenes representan como un aspecto positivo de la universidad el poder convivir con sus compañeros o realizar actividades propias de la institución universitaria, es decir, todo aquello que conforma parte de una vida universitaria. 
Cabe destacar que se hace una clara distinción y un especial énfasis entre algunos aspectos que conforman el ambiente universitario: la carrera que se eligió aparece como el segundo elemento positivo a destacar dentro de la universidad, sin dejar de lado las instalaciones y la calidad de la educación recibida. En el caso particular de los profesores, estos aparecen en ambas categorías que caracterizan lo bueno y malo de la universidad. Los profesores son elemento sustancial en la significación de la educación, se les asigna gran parte del éxito o fracaso de cada uno de los cursos de los que se compone cada una de las carreras.

Los estudiantes asimilan la universidad desde sus componentes de acción y comunicación, es decir, desde las instalaciones, los medios y las personas que posibilitan el cumplimiento de la educación. El compromiso que exigen a los profesores para con su educación determina si se es un buen profesor o no; es una condición de actores donde el cumplimiento de su papel conlleva una fuerte carga social. En este sentido, para poder considerar un imaginario de universidad hay una carga de significación hacia los propios sujetos que la componen: un estudiante que busca una formación y un profesor que desde las significaciones instituidas e instituyentes cobra sentido en relación con el "deber ser» de un buen docente.

Lo que más me desagrada son los profesores mediocres, o sea, porque no dudo de su capacidad intelectual, lo que me asombra es que prefieran no enseñar todo ese conocimiento que saben o no esforzarse por forjar a los alumnos, que eso es su trabajo. Lo que me pregunto es «si no les gusta su trabajo, ¿por qué lo hacen?, ¿para qué están aquí?, mejor que se vayan a hacer otra cosa». Porque nosotros, entiendo que hay veces que no ponemos atención, no le echamos ganas, pero independientemente de eso, si yo soy maestro pues yo quiero que tú aprendas, y si no aprendes, pues no importa, pero al menos ya te di el conocimiento, o sea, de mi parte no quedó el que tú no aprendiste (Alondra, 20 años, CUCEA, Administración Financiera y Sistemas).

Los imaginarios instituidos que podemos ubicar en este discurso es desde el establecimiento de roles de enseñar y aprender; bajo esta condición el proceso de construcción social de lo bueno de la universidad, el prestigio, así como la calidad vienen fijadas en buena parte por la percepción del desempeño que los jóvenes tienen de sus profesores. En el caso de no cumplir con las expectativas se presenta un cuestionamiento directo hacia la capacidad de cumplir con la función instituida de profesor; e incluso, ante la inconformidad por la educación recibida, se pierde el interés por aprender: 
O sea, cuando entre yo creía, bueno como en todo, va a haber maestros buenos, maestros malos; independientemente de los compañeros, porque de ellos siempre hay más variados y cuando entré, hasta eso, se puede decir que tuve unos profesores regulares. Conforme fui avanzando los semestres fue como una decepción brutal porque primero leía las recomendaciones que hacían los mismos alumnos de los profesores y ya agendaba mi horario, pero ya cuando conocía los cursos, no son como decían; yo esperaba más de esos profesores porque pues de eso se tratan las clases, de que te enseñen todo lo que saben, lo que debes saber de ese contenido. Y así, conforme fueron avanzando los semestres fue cada vez peor, porque cada vez que avanzas ves algo como que más de tu carrera, más específico, más especializado, y ya al momento que llegas y te encuentras con un profesor así a estas alturas, o sea, dices: "qué desperdicio de tiempo, de todo». Y sobre todo del tiempo, porque pues ese tiempo lo podrías aprovechar en ver el contenido de esa materia, que aparte que es interesante, lo necesitas para poder seguir en otras materias, o entender conceptos de otras materias, relacionarlos y, sobre todo, de la empresa donde vas a trabajar. Y ya mejor opté por agendar conforme a la hora, o sea, no me importaba el maestro sino la hora (Alondra, 20 años, CUCEA, Administración Financiera y Sistemas).

Como segundo elemento considerado como malo dentro de la universidad está la organización. Dentro de esta categoría se engloban cuestiones como: formas de evaluación (tipologías de créditos), horarios, oferta académica, saturación de materias, trámites burocráticos y líderes estudiantiles. En tercer lugar se encuentra la falta de apoyo por parte de las autoridades universitarias para escuchar necesidades, brindar soluciones, obtener becas, concesiones para quienes trabajan y estudian e incluso falta de materiales didácticos.

Los elementos antes señalados corresponden a construcciones que se realizan desde la experiencia particular; es desde la cotidianidad donde se establece lo que agrada y lo que disgusta a los jóvenes de su universidad. No hay una construcción previa, sino que es en el transcurso de su particular inmersión donde surgen los elementos a considerar para su clasificación como positivos o negativos. Siguiendo esta línea, la universidad queda determinada por la construcción del mundo simbólico que se ha desarrollado a su alrededor y desde esta posición es donde articula su actuar, su discurso y sus representaciones. Los simbólicos instituidos que priman la actividad estudiantil son la adquisición de conocimientos. 


\section{Qué significa ser universitario}

Hasta ahora han quedado delineadas algunas razones por las cuales se elige estudiar una carrera universitaria, así como una serie de significaciones imaginarias sociales sobre las que se construye y representa. Al inclinarse por los imaginarios sociales se priman las relaciones que se van construyendo, así como los procesos sociales que permiten interpretar qué y cómo significan los universitarios. La construcción de esta condición particular de pertenencia a un grupo de universitarios arrojó 14 categorías (figura 2).

Figura 2. Qué significa ser universitario.

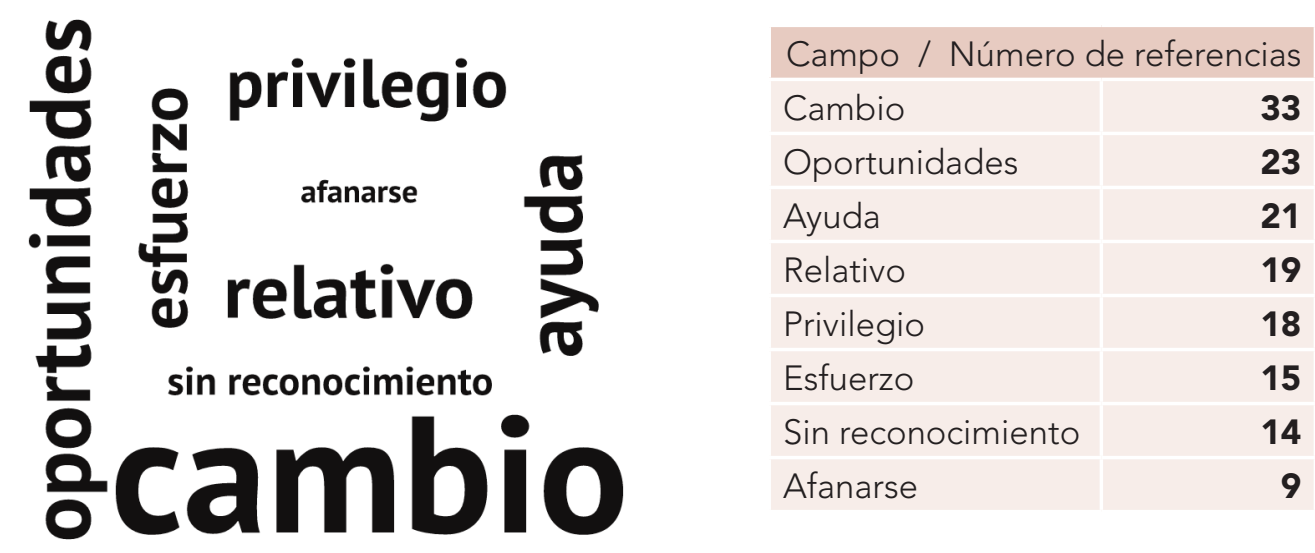

Fuente: Elaboración propia con base en el análisis de las entrevistas.

Como principal elemento, los jóvenes consideran que ser universitario es ser un agente de cambio, un sujeto con la capacidad y la obligación de ayudar a mejorar las condiciones de la sociedad; la responsabilidad social se hace presente:

Creo que significa el cambio. Básicamente, ser un estudiante universitario para mí representa un cambio para el país, porque veo a un México ahorita desarticulado por todas partes; siendo tú un universitario te das cuenta de las dificultades o de algunas dificultades, porque no las puedes ver todas; de algunas dificultades que enfrenta México y toda su sociedad. En este contexto, ahorita, en esta coyuntura tan importante, creo que los estudiantes, esta nueva generación de estudiantes universitarios, tenemos en nuestras manos el organizar todo nuestro sistema, ponernos en serio las pilas y tratar de mejorar la situación, tratar de estabilizar, de disminuir estas brechas 
entre gente extremadamente rica y gente extremadamente pobre; oportunidades de empleo sí las hay, pero son empleos mal pagados, súper explotados. Creo que como una generación de universitarios, algunos que queremos tener nuestras iniciativas propias, tratar de generar nuestras propias empresas, impulsar primeramente en un sector económico; vamos a entrar y vamos a participar, vamos a tratar de generar dinero, de que circule el dinero y posteriormente, ya con nuestro nivel de educación, pues tratar a las generaciones que vienen atrás, pues inculcarles un poquito de que órale, vamos para adelante, pero vamos todos juntos; no se vale que tú te adelantes y que dejes atrás a toda tu banda, o sea, vamos a avanzar todos juntos. Ser estudiante universitario en México significa cambio (Alan, 24 años, CUCSH, Comunicación Pública).

Entre más personas se atrevan a ingresar a la universidad, México puede cambiar; creo que es una frase muy soñadora, pero yo de verdad lo pienso, yo no soy como muchos que piensan que México está perdido, soy muy optimista, soy realista también, pero soy muy optimista en ese sentido y pienso que la educación sí brinda algo más y sí ayuda a los ciudadanos mismos y al fin y al cabo nosotros también somos los que provocamos un cambio. Creo que es algo muy necesario que más personas tengan la oportunidad de ir a la universidad y que puedan aprovecharlo lo más que puedan (Javier, 24 años, CUCSH, Comunicación Pública).

Otra de las principales categorías expuestas es que ser universitario se traduce en oportunidades para conseguir un futuro deseable, bajo la idea instituida de que mediante la educación se puede escalar dentro de la estructura social:

Digamos que es uno de los campos que te ayudan a superarte, obviamente personalmente, académicamente, es como un paso que todos deberíamos de dar para ser mejores en la vida, porque yo creo que todos anhelamos pues eso, el triunfo, que el dinero y todo eso. Entonces, yo creo que la universidad es el paso indispensable si quieres lograr todo eso que te propones (Pamela, 21 años, CUCEA, Turismo).

Entre la significación de los jóvenes existe una separación entre cómo ser universitario en México te brinda oportunidades, generalmente laborales, y cómo, por otra parte, puede ayudarte en tu crecimiento personal. El ser universitario ayuda a fomentar valores, formar un criterio, crea mejores personas, amplía el horizonte, aumenta la calidad de las personas, etc. Esta distinción enmarca una posición de estatus entre los universitarios, una situación instituida que valora al sujeto sobre el nivel de estudios que se hayan adquirido. 
Sin embargo, también se presenta el estado de universitario como relativo, ya que pertenecer a este grupo no implica una diferencia entre las personas; los jóvenes sostienen que es una elección que depende de cada sujeto y de sus condiciones sociales; ellos no consideran que los estudios definan a una persona como buena o mala; son las acciones, habilidades, capacidades, valores e intereses los que articulan las oportunidades y el éxito:

Si la persona quiere hacerlo, está bien, pero ir a la universidad no te hace mejor persona, ni te hace más inteligente tampoco. Creo que es una decisión muy personal, que si bien es cierto está mejor visto que una persona vaya a la universidad a que no vaya, no significa que sea lo más importante. Hay personas que tienen diferentes prioridades en la vida y no debería imponérseles que vayan a la universidad, si no quieren o si no pueden. Sí pienso que es importante que vayan, que traten de experimentar todo eso, que acrecienten su intelecto, pero no tendría que ser, desde mi punto de vista, un requerimiento para decir si esa persona es exitosa, si es buena o si es inteligente (Javier, 24 años, CUCSH, Comunicación Pública).

Como siguiente elemento en la significación está el de ser universitario como un esfuerzo hacia las exigencias que implica ser un estudiante, cumplir con los requerimientos para ingresar a la institución, aprender cada una de las materias y la evaluación constante. Este esfuerzo que realizan los jóvenes muchas veces sienten que no es reconocido por la sociedad, ya que toman en consideración las condiciones adversas que enfrentan los egresados de la universidad, creen que ser universitario en México tiene una falta de reconocimiento:

Que las oportunidades son muy pocas, sí hay, es difícil agarrar una porque eres universitario y apenas vas saliendo, vas comenzando y no tienes experiencia laboral en nada y sí está muy difícil conseguir un trabajo, el sueldo es mal pagado. Hay empresas que no quieren darte nada, ni prácticas, ni nada. Entonces yo creo que estaría bien impulsar un poco esa cultura de que a lo mejor no te pago todo el salario que le pago a un operador normal, pero te pago el setenta por ciento, ya de menos el cincuenta por ciento. Aprendes, te sirve de experiencia y de todos modos estás ganando un dinero porque necesitas solventar tus gastos, de la casa, de la escuela, de lo que sea. Sería dar oportunidad al crecimiento. (Alondra, 20 años, CUCEA, Administración Financiera y Sistemas). 
Ante las desfavorables condiciones que se les presentan, el ser universitarios constituye un orgullo debido a que no todas las personas tienen esa posibilidad. Al ser miembros de ese grupo los individuos adquieren prioridades y significaciones similares, lo que les confiere una identidad social de la cual hay que sentir orgullo, por el privilegio de incursionar en este nivel educativo. A su vez hay una exaltación hacia el ser universitario como forma de dedicación, cuidado de sí y perseverancia de las personas; que implica preocuparse por uno mismo para tratar siempre de sobresalir; una expresión impregnada de afán, no solo a los estudios sino a la propia vida, y es así como también se considera que no todos pueden ser universitarios:

Como te digo, si quieres algo bien para ti pues obviamente tienes que batallarle al principio; no todo te va a llegar tan fácil ni nada; hay gente que puede y no puede cursar la universidad por equis razones, pero yo creo que si pudieras hacerla pues sería un buen paso hasta personal para ti, obviamente, escolar y económico, pero si hasta por personal sería bueno que la gente cursara la universidad (Pamela, 21 años, CUCEA, Turismo).

Dentro de las esferas tradicionales de logro, el ser universitario representa un reconocimiento y un valor agregado a los sujetos; prueba de ello es parte de algunos testimonios en que suponen lo que sería de ellos si no estuvieran dentro de la universidad:

Pues ahorita si no estudias y te quedas con la preparatoria, buscas un trabajo y te van a ofrecer el sueldo mínimo, y para qué te va a servir eso, cuando apenas vas a cubrir tus necesidades y no vas a aspirar a algo más. En cambio, con una licenciatura pues tienes la oportunidad de encontrar algo mejor y poder vivir un poco mejor de como podrías (Carmen, 19 años, CUCEA, Administración Financiera).

Mi vida sería muy diferente si no hubiera estudiado, creo que sí porque hasta la gente te trata diferente. Si te ven que no eres una persona como educada, que no estudiaste nada, te trata diferente a si sabe que eres un universitario ya graduado o no sé. Sí, aparte, yo no sabría muchas cosas y eso es lo que me gusta, aprender cosas nuevas y así (Isabel, 20 años, CUCEA, Negocios Internacionales).

Esta visión pesimista de una vida sin haber podido ingresar a la universidad ayuda a legitimar su importancia y a considerarla como un paso obligado en la 
vida de todo joven en edad de estudiar. La significación que los entrevistados le otorgan a ser universitario pasa por todo un abanico de condiciones que mezclan tanto una visión de esperanza y oportunidades como consideraciones hacia dificultades de autorrealización en un país como México: el papel de los universitarios, el poco reconocimiento, las condiciones de desempleo y falta de apoyo, hasta la mentalidad de la propia sociedad; el ser universitario se convierte así en una motivación de cambio, ya sea personal o social.

\section{Conclusiones}

Los matices que hasta ahora se han presentado como parte del imaginario universitario se construyen a partir de cuestiones muy particulares como expectativas, metas y aspiraciones de sujetos particulares, es decir, desde la propia experiencia; sin embargo, la universidad guarda una estrecha relación con la adscripción y diferenciación hacia un grupo, el poder significar la propia identidad es lo que da sentido al ser universitario, ya no se hace referencia a un sujeto en específico, ahora se significa a una colectividad, un grupo de pertenencia con ciertas características, acciones y funciones dentro de un contexto más amplio, en este caso México.

La realidad de la Universidad de Guadalajara es muy particular, debido a su condición de institución pública. La construcción que se hace de esta parte desde la gratuidad y el prestigio que se ha ido forjando al pasar de los años, aunado al hecho de una firme convicción de concretar la incursión en la educación hasta un nivel universitario; esta idea se encuentra arraigada desde etapas muy tempranas en la vida de los jóvenes entrevistados; en algunos casos se tiene claro desde la infancia la carrera a elegir; sin embargo, también para aquellos que no tienen una idea específica al respecto, la imagen de llegar a la universidad se encuentra bien cimentada. Esta realidad parte de una serie de significaciones imaginarias sociales que han ido instituyéndose a través de largos procesos y, cuando los jóvenes se enfrentan a una sociedad donde se busca el reconocimiento y el cumplimiento de expectativas, aparecen ciertos elementos socialmente aceptables para lograr sus aspiraciones, es decir, acciones con referencia a su entorno. Se tiende a buscar aceptación, reconocimiento de habilidades y aprobación de su grupo más cercano (padres, pareja, maestros y pares). En este discurso la educación cumple la función de proveer de algunos estándares deseables y aceptables 
para la vida, diversas manifestaciones de lo que ellos concederán como éxito en distintos niveles: los ingresos (personal/individual), legado (familia) y reconocimiento (social).

Considero que se requiere llegar a nuevos indicadores sociales que den cuenta de lo que los jóvenes consideran valioso, restableciendo las jerarquías y prioridades que nos permitan saber qué se está haciendo y hacia dónde nos dirigimos. El imaginario social y las representaciones colectivas son una opción que permite dar cuenta de la significación, la creación de imágenes y, por ende, de la acción social. Hay que pensar a los jóvenes y a la sociedad en general desde el lugar que cada uno ocupa en el mundo, así como la capacidad que tienen de cambiarlo. Hombres y mujeres con autonomía, capaces de trazar (imaginar radicalmente) su vida tanto individual como colectiva, poder imaginar y crear un futuro.

Si consideramos cuáles son las consecuencias de este imaginario universitario en un país como México y en el contexto actual nos enfrentamos a serias contradicciones; a pesar de las esperanzas que los jóvenes tienen sobre su futuro, también queda claro que las condiciones no son las óptimas dentro del campo laboral y que México cuenta con circunstancias poco favorables para la mayoría de la población, situación que han denominado como desvalorización de credenciales educativas (Martín-Barbero 2003). Existe un excedente de universitarios para cubrir las plazas de empleo que se crean en México; las exigencias y la competitividad del mercado orillan a los universitarios a optar por autoemplearse, enfocarse a carreras que tengan mayor demanda en el país, cambiar de profesión o continuar preparándose para tratar de insertarse en un campo laboral. La situación del país suele ser considerada como un factor que a veces incide directamente en la elección o el rechazo de determinada carrera:

Yo quería ser fotógrafa pero pues igual, como que a veces me dejo influenciar un poco porque me decían que fotografía, obviamente es carrera pero, si la quería estudiar, no porque me fuera a dedicar tanto a eso porque, a lo que me decían, no es algo bien remunerado, no es de trabajo diario, es algo más como un pasatiempo, y como entonces a veces me dejo llevar por los comentarios y yo creo que por eso no escogí fotografía para dedicarme a eso (Pamela, 21 años, CUCEA, Turismo).

Anteponer las expectativas de futuros deseables, enfocados a una idea que relaciona el éxito con el ámbito económico, a los gustos propios puede ser la causa de que se incrementen los índices de insatisfacción y estrés laboral. Las condiciones actuales mantienen una incapacidad de independencia, donde se sigue 
viviendo con la familia aun después de concluir los estudios. Al revisar los datos de la Encuesta Nacional de Juventud 2010 del Instituto Mexicano de la Juventud (IMJUVE 2011), se reconoce que únicamente 5.6\% de los jóvenes de entre 12 y 29 años viven solos. El Instituto de la Juventud, en su Consulta de Tendencias Juveniles 2013, es más preciso al señalar que $74.27 \%$ de los jóvenes entrevistados aún viven en el hogar familiar; $2.54 \%$ con amigos; $7.38 \%$ viven con su pareja y $5.34 \%$ viven solos. Los jóvenes se ven desencantados al no llevar a cabo sus metas a cabalidad; y a pesar de las condiciones adversas, la educación sigue siendo muy apreciada por su capacidad de formar al sujeto, una experiencia que no se cambia y que se intentaría matricularse las veces que fueran necesarias:

De hecho esta es la tercera vez que hice trámites, el primero sí dije «ay si no quedo, ya no voy a hacer trámites, mejor me dedico a trabajar», pero ya mis papás: «no, es que si tienes que estudiar» y dije un segundo intento y ya si no me quedaba, ahí sí me pegó como de «ah no manches, no me quedé otra vez», pero ya en esta tercera ocasión sí dije: "ya» si no en UdG ya tenía otra universidad de paga obviamente, para ya comenzar mis estudios. Porque ya me había enfadado, ya necesitaba hacer algo de esto (Pamela, 21 años, CUCEA, Turismo).

Agregando la idea instituida de permanecer en el sistema escolar se van definiendo intereses y condiciones de vida que posibilitan o limitan el ingreso a la universidad, lo que va modificando la función de la educación dentro de la vida de los sujetos; y en algunos casos nunca se llega a cuestionar el ingreso y la culminación de una carrera universitaria, esto es, considerado como un paso lógico e indiscutible en la vida. Después del esfuerzo de terminar los estudios universitarios, con las ganas e intenciones de cambiar las condiciones que vive el país, los jóvenes salen a una sociedad que no reconoce del todo su trabajo o simplemente no cuenta con los espacios para que se puedan desarrollar los universitarios (Pieck 2001, Jacinto 2002, Suárez y Pérez 2008, Suárez 2005).

La limitante de autorrealización no solo atañe a los universitarios; sus familias también se ven involucradas cuando los jóvenes sin empleo o con uno por debajo de sus expectativas deben permanecer en casa de los padres. En algunos casos siguen dependiendo económicamente de ellos, lo que se le conoce como desempleo ilustrado, condición que limita el acceso de los universitarios al campo laboral por su propio nivel educativo. Ulrich Beck (2008:29) señala: «la inseguridad creciente, que se está convirtiendo en la experiencia básica de las generaciones más jóvenes, no es un fenómeno local, regional o nacional. Más 
bien, esta inseguridad se está convirtiendo en una experiencia clave y común, que trasciende fronteras y que podemos resumir en las palabras unidos en el declive». Sin embargo, la instauración del imaginario también permite a los jóvenes darle sentido y dirección a su actuar mediante las significaciones instituidas, es decir, la universidad como medio legitimo para obtener éxito. La condición instituida es necesaria en toda sociedad porque establece los parámetros comunes y socialmente aceptados, pero esta condición no es absoluta y se ve modificada al ser interiorizada por los sujetos. Aprender a leernos y pensarnos desde nuestros propios contextos culturales nos ayudará a identificar los verdaderos problemas que se presentan en el tejido social.

\section{Fuentes de consulta}

Andere, Eduardo, 2003, La educación en México: un fracaso monumental. ¿Está México en riesgo?, México, Planeta Mexicana.

ANUIES, 2006, Consolidación y Avance de la Educación Superior en México, México, Asociación Nacional de Universidades e Instituciones de Educación Superior.

Anzaldúa, Raúl, 2007, "Lo 'imaginario' en la investigación educativa», Memoria IX Congreso COMIE, México.

Anzaldúa, Raúl (coord.), 2010, Imaginario social: creación de sentido, México, Universidad Pedagógica Nacional.

Anzaldúa, Raúl y Ramírez, Beatriz, 2016, «Reflexiones sobre la investigación de lo imaginario», en Luis Pérez y Gustavo Enríquez (coords.), Imaginario social y representaciones sociales. Teorías sobre el saber cotidiano, Morelos, UAEM / Books and Chips, disponible en <http://libros.uaem.mx/?product=imaginario-social-y-representaciones-sociales-teorias-sobre-el-saber-cotidiano> [consulta: 25/03/2017].

Baczko, Bronislaw, 1991, Los imaginarios sociales: Memorias y esperanzas colectivas, Buenos Aires, Nueva Visión.

Baeza, Manuel, 2000, Los caminos invisibles de la realidad social. Ensayo de sociología profunda sobre los imaginarios sociales, Santiago de Chile, Ril.

Beck, Ulrich, 2008, "Generaciones globales en la sociedad del riesgo mundial», CIDOB d'Afers Internacionals, 82-83, Barcelona, Fundación CIDOB.

Berger, Peter y Thomas Luckmann, [1966] 2003, La construcción social de la realidad, Buenos Aires, Amorrortu.

Cabrera, Daniel, 2006, Lo tecnológico y lo imaginario: las nuevas tecnologías como creencias y esperanzas colectivas, Buenos Aires, Biblos.

Castoriadis, Cornelius, [1964] 1983, La institución imaginaria de la sociedad. Vol. 1. Marxismo y teoría revolucionaria, Barcelona, TusQuets.

Castoriadis, Cornelius, 1989, La institución imaginaria de la sociedad. Vol. 2. El imaginario social y la institución, Barcelona, TusQuets. 
Castoriadis, Cornelius, 1994, Los dominios del hombre: Las encrucijadas del laberinto, Barcelona, Gedisa.

Durkheim, Emile, 1898, "Représentations individuelles et représentations collectives», Revue de Métaphysique et de Morales, VI, París.

Flores, Pedro, 2005, Educación superior y desarrollo humano: el caso de tres universidades tecnológicas, México, Asociación Nacional de Universidades e Instituciones de Educación Superior.

Franco, Yago, 2003, Magma. Cornelius Castoriadis: psicoanálisis, filosofía, política, Buenos Aires, Biblos.

Instituto de la Juventud, 2013, Consulta de Tendencias Juveniles 2013, CDMX, México, disponible en <https://issuu.com/injuvecdmx/docs/consulta-tendencias-juveniles-2013> [consulta: 22/08/2016].

Ibarra, Eduardo, 2006, «Educación superior, entre el mercado y la sociedad: apuntes para imaginar su función social», Revista de la Educación Superior, 35(138), pp. 123-133.

IMJUVE, 2011, Encuesta Nacional de Juventud 2010. Resultados Generales, México, Instituto Mexicano de la Juventud.

INEGI, 2013, Encuesta Nacional de Ocupación y Empleo. Indicadores estratégicos, disponible en <http://www.inegi.org.mx/sistemas/bie/cuadrosestadisticos/GeneraCuadro. aspx?s=est\&nc $=601 \& c=25444>$ [consulta: $22 / 08 / 2016$ ].

Jacinto, Claudia, 2002, «Los jóvenes, la educación y el trabajo en América Latina. Nuevos temas, debates y dilemas», en María Ibarrola (coord.), Desarrollo local y formación. Hacia una mirada integral de la formación de los jóvenes para el trabajo, Montevideo, DIE-Cinvestav/Cinterfor-OIT/Universidad Iberoamericana León/Red Latinoamericana de Educación y Trabajo, pp. 67-103.

Jodelet, Denise, [1984] 1986, «La representación social: fenómeno, concepto y teoría», en Serge Moscovici (comp.), Psicología Social II, Barcelona, Paidós, pp. 469-494.

Martín-Barbero, Jesús, 2003, Oficio de cartógrafo. Travesías latinoamericanas de la comunicación en la cultura, México, Fondo de Cultura Económica.

Moscovici, Serge, [1961] 1979, El psicoanálisis, su imagen y su público, Buenos Aires, Huemul.

Pérez, Luis y Gustavo Enríquez (coords.), 2016, Imaginario social y representaciones sociales. Teorías sobre el saber cotidiano, Morelos, Universidad Autónoma del Estado de Morelos.

Pieck Gochicoa, Enrique (coord.), 2001, Los jóvenes y el trabajo. La educación frente a la exclusión social, México, UIA/IMJ/UNICEF/Cinterfor-OIT/RETLA/Conalep.

Pintos, Juan-Luis, 2000, "Construyendo realidad(es): los imaginarios sociales», GCEIS-Papeles de trabajo, 1, 1-21, Santiago de Compostela, disponible en <https://www. academia.edu/943259/Construyendo_realidad_es_los_imaginarios_sociales> [consulta: 22/08/2016].

Pintos, Juan-Luis, 2004, «Inclusión-exclusión. Los imaginarios sociales de un proceso de construcción social», SEMATA. Ciencias sociales e humanidades, 16, pp. 17-52, Santiago de Compostela, disponible en <https://www.academia.edu/943263/ Inclusion-exclusion_Los_imaginarios_sociales_de_un_proceso_de_construcci\%C3\%93n_social> [consulta: 22/08/2016]. 
Pintos, Juan-Luis, 1995, Imaginarios Sociales. La nueva construcción de la realidad social, Madrid, Fe y Secularidad.

Poirier, Nicolás, 2004, Castoriadis: El imaginario radical, Buenos Aires, Nueva Visión.

Suárez Zozaya, María, 2005, Jóvenes mexicanos en la feria del mercado de trabajo. Conveniencias e inconveniencias del tener educación superior, México, SES/UNAM.

Suárez Zozaya, María y Pérez Islas, José Antonio (coords.), 2008, Jóvenes Universitarios en Latinoamérica, hoy, México, UNAM/Miguel Ángel Porrúa.

Tello, Nerio, 2003, Cornelius Castoriadis y el imaginario radical, Madrid, Campo de ideas. 